\title{
An Optimization Study on Syngas Production and Economic Evaluation
}

\author{
Faraz Qasim, Jae Sun Shin, Jong Hwa Jeong and Sang Jin Park \\ Deptartment of Chemical Engineering, Dongguk University, 26, Pil-dong 3-ga, Jung-gu, Seoul 100-715, Korea
}

\begin{abstract}
Syngas production in Gas-to-liquid (GTL) process is focused in past by several researchers to increase the production with minimal capital and operating costs. In this study, syngas production process is simulated and optimized to increase its production and the economic analysis is studied for the proposed optimized process. Aspen HYSYS v8.4 is used for all process simulation work in this article. A new configuration is rigorously simulated while using auto-thermal reforming. Results exhibit a tremendous rise in production of syngas.
\end{abstract}

\section{Introduction}

The gas-to-liquid (GTL) technology has gained much attraction due to recent rise of crude oil prices. Many energy related companies have shown their interest in gas-to-liquid technology in recent time and as a result many large scale industrial facilities are producing synthetic oil by using natural gas. The natural gas reserves are being utilized now to be converted to useful liquid products by using GTL process [1]. Franz Fischer and Hans Tropsch developed the FT (Fischer Tropsch) process which acts a key role to convert syngas into range of hydrocarbons [2], [3]. In industry, syngas can be produced by different methods; partial oxidation, dry reforming and steam methane reforming while the combination of two or more aforementioned processes can also be utilized for production of syngas e.g autothermal reforming (ATR), tri-reforming, gas heated reforming (GHR) [4]. The raction rate and the overall conversion is higher in ATR than the steam reforming process due to that fact that the exothermic combustion reactions occur in the ATR reactor [5-7]. A mixture of $\mathrm{CO}, \mathrm{H} 2, \mathrm{CO} 2$ with traces of some unconverted components are obtained as a result of all reforming technologies. ATR technology is most used method as it produces the $\mathrm{H} 2 / \mathrm{CO}$ ratio of 2 . Hence, the ratio produced and process conditions match well with the FT reactor. The overall reaction rates in ATR are also better than other reformer types. ATR process is usually considered favorable for production of synthesis gas. Synthesis gas in the desired range can be produced by using ATR. Moreover, the floating production facilities prefer ATR due to its compact size. In recent time, ATR technology is being operated by various license holders like Haldor Topsie and Linde.

The other useful process for producing synthetic gas is stream reforming which has a long history of being used in process industries. It has advantage over other processes that it uses steam for production of carbon monoxide, carbon dioxide and hydrogen. The other processes consume oxygen as an external utility for conversion of natural gas and the use of oxygen leads to environmental hazards. The use of technologies like ATR and partial oxidation also leads to carbon deposition, safety issues and catalyst destruction [8]-[10]. Another advantage of steam reforming can be in the form of hydrogen produced in the process which can be further consumed in the upgrading step of GTL process.

\section{Process description}

Autothermal reforming of natural gas produces range of syngas composition due to which it is considered useful in the gas to liquid applications. An improved design of autothermal reforming process is proposed and its optimization is done to make it more economical. The production of syngas is increased and two cases are compared on the basis of different configurations.

The partial oxidation and steam methane reforming reactions $[11,12]$ occur in ATR process. The reactions are shown below:

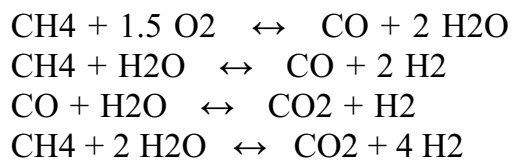

The Kinetics applied for the catalytic reforming reactions are taken from $\mathrm{Xu}$ and Froment [13]. The simulation of the syngas production process is run by Aspen HYSYS v8.4. Fig. 1 depicts the process simulation of the syngas production process with recycling technique and heat integration. While Fig. 2 shows the conventional design for synthesis gas production. For simulating the process, Peng-Robinson [14] property package is utilized in Aspen HYSYS 
simulator. In the proposed design (Fig. 1), natural gas and steam are introduced at temperature $400{ }^{\circ} \mathrm{C}$ and $300{ }^{\circ} \mathrm{C}$, respectively, while the pressure in this design is 25 bar. PFR-100 is reformer, while X-100 and X-101 are hydrogen removal unit and $\mathrm{CO}$ removal unit, respectively. For reactor, PFR model is utilized and the product stream from reactor leave at temperature $715{ }^{\circ} \mathrm{C}$ and pressure $2500 \mathrm{kPa}$. A process to process heat transfer method is also utilized in this design to make this process optimized unlike previously proposed designs in literature. Hence, temperature for stream 3 and oxygen stream is raised up to $598^{\circ} \mathrm{C}$ and $200^{\circ} \mathrm{C}$, respectively. After the partial oxidation, natural gas is introduced to reformer where it is converted to syngas. In this work, conventional GTL process is coupled with the recycling technique which includes recycling of tail gas to auto-thermal reformer due to which the molar flows of the syngas are increased while the $\mathrm{H} 2 / \mathrm{CO}$ ratio still remains same as 2 .

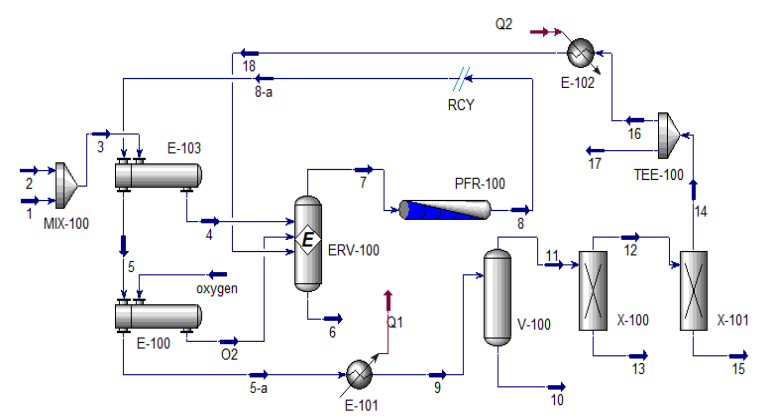

Figure 1. Autothermal reforming process for syngas production with tail gas recycled (optimized design)

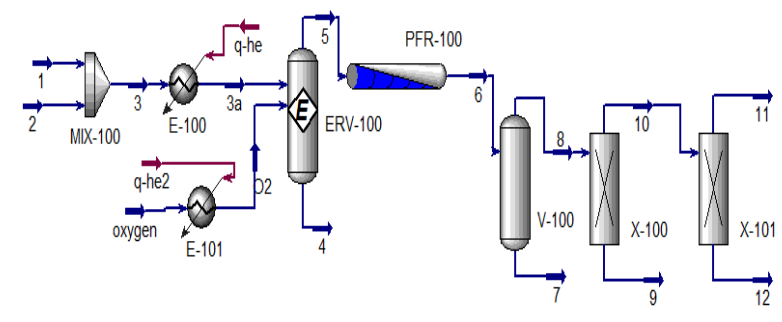

Figure 2.Autothermal reforming process for synthesis gas production with conventional design

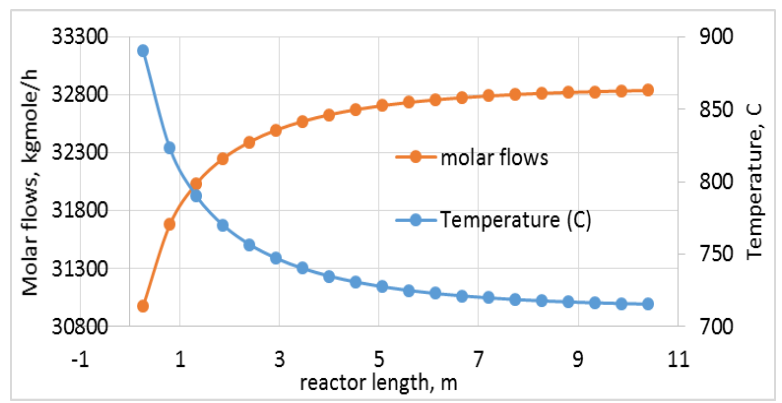

Figure. 3. Reactor length vs molar flows and temperature

In proposed design (Fig. 1), Hydrogen is recovered as bottom product of X-100 unit while the carbon dioxide is recovered in the bottom of X-101 unit. The product stream from the combustion reactor leaves at $1109{ }^{\circ} \mathrm{C}$ and it enters PFR. The conversion of methane in PFR results into $98 \%$ and the product stream from PFR is at high temperature i.e $715.6^{\circ} \mathrm{C}$. A different configuration is proposed to cool down this stream and two heat exchangers are utilized in the process. The process with and without heat exchangers are simulated and the economic aspects of both processes are analyzed. The recycled tail gas mainly constitutes unconverted methane, hence, the recycling provides an increased production in an optimized design. The recycling technique is proposed to increase the volumetric production of syngas. A conventional process is also designed and its production and operating costs are analyzed.

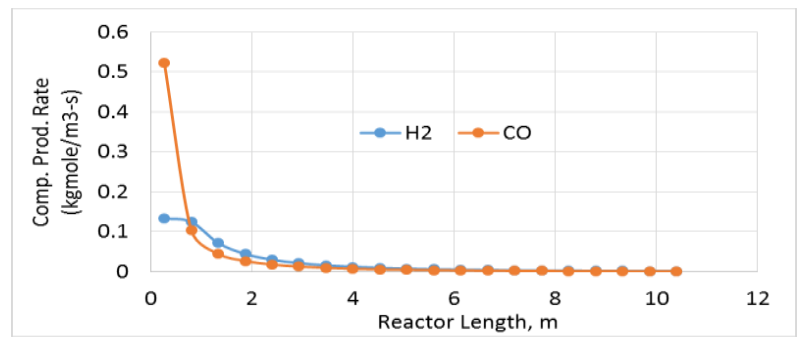

Figure. 4. Reactor length vs comp. prod. rate

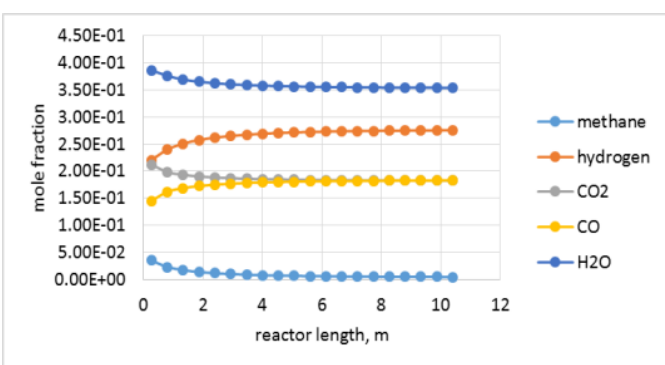

Figure 5.Reactor length vs compositions of components.

It can be observed that the conventional design is utilizing external hot steam to meet the energy requirements. Hence, the capital cost and operating cost of the system get increased while using conventional design for syngas production by autothermal reforming process. Feed temperature is increased because of the high temperature requirement in the reactor. Oxygen feed is also heated upto $200{ }^{\circ} \mathrm{C}$ for process requirement.

\section{Results and discussions}

The desired composition of syngas is produced and optimization is done for whole process. Fig. 3, 4 and 5 show the relation of molar flows, temperature, reaction rates and mole fractions of different components with varying reactor length. Fig. 3 explains the relation of the temperature and molar flows along the reactor length. The temperature along the reactor decreases as the length of the reactor increases. While the molar flows show a direct relation towards the reactor length. Hence, the reactor length plays an important role for the operating conditions of the process. Fig. 4 exhibits the relation of the product component rates along the reactor length.

The optimization work is done to optimize the operating conditions of the process. Furthermore, the 
fixed capital cost can also be decreased by using optimization techniques. The small reactor length shows the high flow rates for the product components while increasing the reactor length will results into less flow rate of the product components. As the process deals with components like hydrogen, carbon dioxide, methane, corbon monoxide and water, there is a need to optimize the reactor length for all these compoents. The Fig. 5 demystifies the effect of reactor length on compositions of all the componets dealt in the process. Hydrogen and carbon monoxide exhibit a direct relation to the reactor length while the other components' composition get decreased as the reactor length increases. Table 1 shows optimziation work for the effect of reactor length on temperature and Table 2 exhibits the simulation results for the compositions of all components in reactor.

Table 1. Optimization work for reactor length vs temperature

\begin{tabular}{|c|c|c|c|c|c|}
\hline Reactor length $(m)$ & methane & hydrogen & $\mathrm{CO}_{2}$ & $\mathrm{CO}$ & $\mathrm{H}_{2} \mathrm{O}$ \\
\hline 0.26 & $3.50 \mathrm{E}-02$ & 0.22 & 0.21 & 0.14 & 0.38 \\
\hline 0.80 & $2.32 \mathrm{E}-02$ & 0.24 & 0.19 & 0.16 & 0.37 \\
\hline 1.33 & $1.74 \mathrm{E}-02$ & 0.25 & 0.19 & 0.16 & 0.36 \\
\hline 1.86 & $1.40 \mathrm{E}-02$ & 0.25 & 0.19 & 0.17 & 0.36 \\
\hline 2.40 & $1.17 \mathrm{E}-02$ & 0.26 & 0.18 & 0.17 & 0.36 \\
\hline 2.93 & $1.01 \mathrm{E}-02$ & 0.26 & 0.18 & 0.17 & 0.36 \\
\hline 3.46 & $8.93 \mathrm{E}-03$ & 0.26 & 0.18 & 0.17 & 0.35 \\
\hline 4.00 & $8.04 \mathrm{E}-03$ & 0.26 & 0.18 & 0.17 & 0.35 \\
\hline 4.53 & $7.35 \mathrm{E}-03$ & 0.27 & 0.18 & 0.18 & 0.35 \\
\hline 5.06 & $6.80 \mathrm{E}-03$ & 0.27 & 0.18 & 0.18 & 0.35 \\
\hline 5.60 & $6.37 \mathrm{E}-03$ & 0.27 & 0.18 & 0.18 & 0.35 \\
\hline 6.13 & $6.03 \mathrm{E}-03$ & 0.27 & 0.18 & 0.18 & 0.35 \\
\hline 6.66 & $5.75 \mathrm{E}-03$ & 0.27 & 0.18 & 0.18 & 0.35 \\
\hline 7.20 & $5.52 \mathrm{E}-03$ & 0.27 & 0.18 & 0.18 & 0.35 \\
\hline 7.73 & $5.33 \mathrm{E}-03$ & 0.27 & 0.18 & 0.18 & 0.35 \\
\hline 8.26 & $5.18 \mathrm{E}-03$ & 0.27 & 0.18 & 0.18 & 0.35 \\
\hline 8.80 & $5.05 \mathrm{E}-03$ & 0.27 & 0.18 & 0.18 & 0.35 \\
\hline 9.33 & $4.95 \mathrm{E}-03$ & 0.27 & 0.18 & 0.18 & 0.35 \\
\hline 9.86 & $4.86 \mathrm{E}-03$ & 0.27 & 0.18 & 0.18 & 0.35 \\
\hline 10.40 & $4.79 \mathrm{E}-03$ & 0.27 & 0.18 & 0.18 & 0.35 \\
\hline
\end{tabular}

Table 2. Compositiions for all components vs reactor length

\begin{tabular}{|c|c|c|c|c|c|c|c|c|c|c|c|}
\hline Reactor Length (m) & 0.26 & 0.80 & 1.33 & 1.86 & 2.40 & 2.93 & 3.46 & 4.00 & 4.53 & 5.06 & 5.60 \\
\hline Temperature (C) & 890.23 & 823.26 & 790.23 & 770.17 & 756.79 & 747.31 & 740.30 & 734.97 & 730.86 & 727.61 & 725.03 \\
& & & & & & & & & & & \\
\hline
\end{tabular}

The heat supplied from external sources is optimized to make the process energy efficient. The process to process heat transfer shows promising results in optimization procedure. The heat exchangers E-103 and E-100 are utilized in simulation of whole process to exchange heat with the process streams. Hence, the external steam requirements are tremendously decreased. The process to process heat transfer and heat integrations have been studied by various researchers in past literature [15], [16]. The heat integration can be done by using heat pumps or by using process to process heat transfer. A heat pump can be added to the system which increases the heat quality provided to reboiler. The heat pump can be absorption heat pump or mechanical heat pump. Mechanical heat pump makes use of vapor recompression technique which is very efficient way to save external steam and hot utilities. The product stream pressure can be increased by the compressor which provides heat to the process streams. But the use of compression system increases the overall cost of the system and hence it makes process economically unattractive. Hence, compression system is not used in this work and the heat exchangers are utilized to exchange the heat within the process.

The heat exchanger E-103 is utilized to increase the temperature of the feed stream from $348.1^{\circ} \mathrm{C}$ to $598.1^{\circ} \mathrm{C}$ and this heat stream 4 is then fed to the reactor. While the other heat exchanger E-100 is utilized to heat up the oxygen feed from $20^{\circ} \mathrm{C}$ to $200^{\circ} \mathrm{C}$. The stream 5 which still has the high heating potential is then used to heat up oxygen feed in E-100. As a result, temperature of stream 5 -a is decreased.

In this work, the production rate of syngas in the designed process is found out to be approximately 11570 $\mathrm{kgmol} / \mathrm{h}$. After sizing and mapping of all equipments, economic evaluation is also done and objective function is defined to analyze economics.

An objective function is defined to analyse the economic aspects of both designs and the profit. The mathemical formulation representing objective function is given in equation 5 .

$$
\text { Objective function }=\mathrm{PR}-\mathrm{RM}-\mathrm{Ut}-\mathrm{CD}
$$


Product revenue (PR), described in equation 5 , is the price of the product recovered in the product stream and it is defined in equation 6 .

$$
\text { Product revenue }=\sum P_{\text {product }} F_{\text {product }}
$$

where $\mathrm{P}$ is the price of the product in product stream and $\mathrm{F}$ is the flow rate of the product. Raw material RM cost is used in the objective function and it is defined in equation 7.

$$
\text { Raw material cost }=\sum C_{\text {feed }} F_{\text {feed }}
$$

Equation 7 defines raw material cost as the product of cost of feed components and the flow rate of feed components.

Furthermore, Utility cost is another important factor which is considered in the economic analysis. The utility cost is cost of the steam and cold water used in the process. As the optimization work is done in this simulation study, cost of steam is optimized and the requirement of steam and cold water is decreased as much as possible. The utility cost is defined in equation 8 .

$$
\text { Utility Cost }=\sum C_{\text {Utility }}
$$

Equation 5 makes use of capital depreciation CD which is defined as the product of the capital cost of the equipment and the depreciation factor. The depreciation factor is found from the Aspen HYSYS economic analyzer and the $\mathrm{CD}$ is found by using following equation.

$$
\text { Capital depreciation }=\sum C_{\text {equipment }} D
$$

Where $\mathrm{C}$ is the cost of the equipment and $\mathrm{D}$ is depreciation factor.

Economic evaluation of the syngas production process is done by using Aspen HYSYS Process Economic Analyzer. First, all the equipment are sized and mapped according to the process conditions. Economic analysis is done for the optimized processes and the optimized variables are first fixed in the simulation flow sheets.

The conventional process exhibits the project capital cost of $1.96 \mathrm{E}+06$ USD and operating cost of $1.44 \mathrm{E}+06$ USD/year. The total utilities consumed in this design cost up to $4.9 \mathrm{E}+05 \mathrm{USD} /$ year. Electricity requires 4.05 USD/hour while steam needed in the process costs 51.72 USD/hour. The optimized process (Fig. 1) is the solution for high steam cost and this design does not use external hot steam for process requirements. The economic analysis shows that the conventional process is very expensive than the optimized model using recycling and heat integration. The project capital cost and operating cost of optimized design (Fig. 1) is found to be $1.26 \mathrm{E}+06$ USD and 9.14E+05 USD/year, respectively. The desired rate of return in this design is found out to be 20 percent/year. For calculating capital depreciation, the depreciation factor found in economic analysis is $2.5 \mathrm{E}+05$ per year. The depreciation factor is calculated by straight line method.
The maintenance cost and operating labor cost are the major factors which are needed in economic analysis. In the optimized process, the operating cost and the maintenance cost are found to be $1.94 \mathrm{E}+03 \mathrm{USD}$ and 4.82E+05 USD, respectively. Moreover, the insulation cost, contingency and the instrumentation costs are calculated to be $2.30 \mathrm{E}+04,2.45 \mathrm{E}+05$ and $1.61 \mathrm{E}+05 \mathrm{USD}$, respectively.

As the heat integration has also been applied in the process, there is no usage of external steam to heat up the streams. All the heating requirements are met within the process by process to process heat transfer. Hence, the external utility includes only electricity and cooling water. Electricity consumption costs $4.05 \mathrm{USD} /$ hour while the cooling water costs $785.82 \mathrm{USD} /$ hour in the designed process for syngas production. The objective function is used to compare the profit of the process with and without heat integration and the process with heat integration exhibits more profit.

In this study, aspen HYSYS simulations of different configurations, optimization work and economic analysis are performed. The optimized model using recycling techniques and heat integration exhibit $14 \%$ more profit than the process without recycle streams and heat integration. Hence the operating cost can be decreased by the proposed design in this simulation study.

\section{Conclusions}

A design for autothermal reformer for GTL process is developed alongwith optimizations to make the process economically favorable. Simulation of conventional and optimized design is done for syngas prodcution. Tail gas recycling configuration gives the most optimized process design with $\mathrm{H} 2 / \mathrm{CO}$ ratio of 2 . The recycling method used in this study increases the production of the syngas. Process to process heat transfer is also done to optimize the utility requirements and the results show that the proposed model requires less utilities than the designs proposed in previous literature. The economic aspects of the process are utilized too and it unveils the total operating cost and total capital cost of the process. The proposed design using recycle technique and heat integration exhibits $14 \%$ more profit than the conventional design. Moreover, the volumetric production of syngas has been improved in this work.

\section{References}

1. H. Schulz; Short history and present trends of Fischer-Trosch synthesis, Applied Catalysis A, 186, 3-12 (1999).

2. M. E. Dry; The Fischer Tropsch Process: 1950-2000, Catalysis Today, 71, 227-241 (2002).

3. T. Takeshita, K. Yamaji; Important roles of FischerTropsch synfuels in the global energy future, Energy Policy, 36, 2773- 2784 (2008).

4. A. P. E. York, T. C. Xiao, M. L. H. Green, J. B. Claridge,; Methane oxyreforming for synthesis gas production, Catal. Rev. Sci. Eng., 49, 511-560 (2007). 
5. X. Song, Z. Guo; Technologies for direct production of flexible hydrogen/CO synthesis gas, Energy Conversion and Management, 47, 560-569 (2006).

6. K. Aasberg-Petersen, T. S. Christensen, C. S. Nielsen, I. Dybkjaer,; Recent developments in autothermal reforming and pre-reforming for synthesis gas production in GTL applications, Fuel Process. Technol., 83, 253-261 (2003).

7. Y. Patcharavorachot, M. Wasuleewan, S. Assabumrungrat,

A. Arpornwichanop; Analysis of hydrogen production from methane autothermal reformer with a dual catalyst-bed configuration, Theor. Found. Chem. Eng., 46,658-665 (2012).

8. Padban, N.; Becher, V. Clean Hydrogen-Rich Synthesis Gas ;Chris Gas Report, (2005).

9. Zhu, Q.; Zhao, X.; Deng, Y. Advances in the Partial Oxidation of Methane to Synthesis Gas.J. Nat. Gas Chem., 13, 191 - 203 (2004).

10. Van Hardeveld, R. M.; Groeneveld, M. J.; Lehman, J. Y.; Bull, D. C. Investigation of an Air Separation Unit Explosion. J. Loss Prev. Process Ind., 14, 167 180 (2001).
11. W. Maqbool \& E. S. Lee, Syngas Production Process Development and Economic Evaluation for Gas - to - Liquid Applications. Chemical Engineering \& Technology, 37, 995-1001 (2014).

12. J. Pina, D. O. Borio; Modeling and simulation of an autothermal reformer, Latin Am. Appl. Res., 36, 289-294 (2006).

13. J. Xu, G. F. Froment; Methane steam reforming, methanation and water-as shift: I. Intrinsic kinetics, AIChE J., 35, 88-96 (1989).

14. J. N. Jaubert; F. Mutelet. VLE predictions with the Peng-Robinson equation of state and temperature dependent calculated through a group contribution method. Fluid Phase Equilibria, 224, 285-304 (2004).

15. F. Qasim, J. S. Shin, S. J. Cho, \& S. J. Park, Optimizations and heat integrations on the separation of toluene and 1-butanol azeotropic mixture by pressure swing distillation. Separation Science and Technology, 51, 316-326 (2016)

16. T. O. Omideyi; J. Kasprzycki, F. A. Watson, The economics of heat pump assisted distillation systems I. A design and economic model. J Heat Recov Syst., 4, 187 -200 (1984). 